\title{
Morphological Evaluation of Silicone/Clay Slurries by Small-angle/Wide-angle X-ray Scattering
}

\author{
Manuela L. Q. A. Kaneko, ${ }^{a}$ Íris L. Torriani ${ }^{b}$ and Inez V. P. Yoshida ${ }^{*, a}$ \\ ${ }^{a}$ Instituto de Química, Universidade Estadual de Campinas, CP 6154, 13084-971 Campinas, SP, Brazil \\ ${ }^{b}$ Instituto de Física, Universidade Estadual de Campinas, CP 6165, 13084-971, \\ Campinas, SP, Brazil and Laboratório Nacional de Luz Síncrotron (LNLS), Campinas, SP, Brazil
}

\begin{abstract}
Pastas de argilas em siliconas foram obtidas por mistura mecânica de diferentes fluidos de silicona e argilas montmorillonitas. Duas séries de pastas contendo (1) montmorillonita natural (MMT) e (2) montmorillonita orgânica (O-MMT) foram preparadas usando poli(dimetilsiloxano) com finais de cadeias $\mathrm{Si}\left(\mathrm{CH}_{3}\right)_{2} \mathrm{OH}$ (PDMS-OH), poli(dimetilsiloxanoco-metilpropilóxido de etileno siloxano) (PDMS-PEO) ou emulsão de poli(dimetilsiloxanoco-aminoetilaminopropilmetilsiloxano) em água (PDMS- $\mathrm{NH}_{2}$ ). A morfologia das pastas foi caracterizada por espalhamento de raios-X em baixo/alto ângulo usando detector bidimensional (SAXS/WAXS-2D). As pastas preparadas com PDMS-OH apresentaram apenas um aumento discreto na separação das lamelas, enquanto aquelas preparadas com PDMS-PEO e PDMS-NH $\mathrm{NH}_{2}$ apresentaram um aumento pronunciado, resultando em tactóides expandidos. Além disso, a análise da região de SAXS indicou a presença de lâminas finas (lamelas esfoliadas e/ou empilhamento de poucas lamelas) e tactóides expandidos nas pastas MMT/PDMS-PEO e MMT/PDMS- $\mathrm{NH}_{2}$. Esta estrutura hierárquica também foi encontrada nas pastas preparadas com a O-MMT.
\end{abstract}

Silicone/clay slurries were prepared by mechanical blending of different silicone fluids and montmorillonite clays. Two dispersion series containing (1) a natural montmorillonite (MMT) and (2) an organic montmorillonite (O-MMT) were prepared using poly (dimethylsiloxane) with $-\mathrm{Si}\left(\mathrm{CH}_{3}\right)_{2} \mathrm{OH}$ end groups (PDMS-OH), poly(dimethylsiloxane-comethylpropylethylene oxide siloxane) (PDMS-PEO) or a poly(dimethylsiloxane-coaminoethylaminopropylmethylsiloxane)/water emulsion $\left(\mathrm{PDMS}-\mathrm{NH}_{2}\right)$ as dispersion fluids. The resulting morphology of the silicone/clay slurries was characterized by small-angle/ wide-angle X-ray scattering using a two-dimensional imaging plate detector (2D-SAXS/ WAXS). The PDMS-OH/clay slurries showed only a slight increase in the layer separation while a more pronounced effect was found for the PDMS- $\mathrm{NH}_{2}$ and PDMS-PEO slurries, which resulted in expanded tactoids. Analyses in the SAXS region also indicated the existence of thin platelets for the MMT slurries prepared with PDMS-NH $\mathrm{N}_{2}$ and PDMS-PEO fluids. This hierarchical structure, formed by thin platelets and expanded tactoids, was also found in the O-MMT/silicone slurries.

Keywords: montmorillonite, silicone, SAXS/WAXS

\section{Introduction}

The complexity of the crystalline structure of layered clays results in many interesting structural features like the presence of hydroxyl groups, Lewis and Brönsted acidities and the existence of exchanged interlayer cations. In addition, the high aspect ratio of clay minerals and the small dimensions of the individual layers make them particularly attractive in several areas of materials science. ${ }^{1}$

*e-mail: valeria@iqm.unicamp.br
Considering the wide range of applications of layered silicates, efforts have recently focused on the preparation of polymer-layered silicate nanocomposites using natural or synthetic clay minerals., ${ }^{2,3}$

Among clays used to prepare polymer-layered silicate nanocomposites, montmorillonites attract the most attention mainly due to their natural availability. The pristine morphology of montmorillonite is formed by stacked tactoids that are built from the face-to-face stacking of the clay layers. Each layer consists of two tetrahedrally coordinated silicon atoms fused to an edge- 
shared octahedral sheet of either aluminum or magnesium hydroxide. The layer thickness is around $10 \AA$, and the lateral dimensions vary from 1000 to $1500 \AA$. Stacking of the layers leads to a regular gap between the layers called a gallery. The galleries are normally occupied by cations that balance the charge deficiency generated by isomorphous substitution within the layers (for example, $\mathrm{Si}^{4+}$ replaced by $\mathrm{Al}^{3+}$, or $\mathrm{Al}^{3+}$ replaced by $\mathrm{Mg}^{2+}$ or $\mathrm{Fe}^{2+}$ ).,

From the structural point of view, two ideal morphologies, defined as intercalated and exfoliated, are commonly used to describe the state of the clay dispersion in a polymeric matrix. In the intercalated structure, polymeric chains are inserted into the gallery space between the individual silicate layers. In contrast, in the exfoliated structure the individual clay layers are dispersed in the polymeric matrix. In many systems, the physical polymer-layered silicate mixture may not form a nanocomposite. In this situation the incompatibility between polymer and clay may produces clay agglomerates dispersed in the polymeric matrix. ${ }^{2,3}$

In order to prepare polymer-layered silicate nanocomposites, several approaches are used: $(i)$ solution intercalation, (ii) monomer intercalation and subsequent polymerization, or (iii) polymer intercalation and compounding. ${ }^{2,3}$ In some cases, polymer melts can intercalate directly, unassisted by shear or solvents. This fact is rather surprising as it implies that polymer chains can undergo large center-of-mass displacement (up to several micrometers) in quasi two-dimensional interstices. ${ }^{4}$

Another method to prepare polymer-clay nanocomposites is slurry (clay dispersion) polymer compounding. In this technique the clay slurry is directly compounded with the polymer. It was first reported by Hasegawa et al..$^{5}$ for nylon/clay and recently was described for the preparation of epoxy/clay ${ }^{6-8}$ and silicone/clay composites. ${ }^{9}$ The basic idea is to increase the clay interlayer spacing at the first stage of the process, by polymerization of monomers or suspension of the clay in water/solvents and then the polymeric matrix intercalates in this enlarged clay spacing. ${ }^{9}$

Ma et al. ${ }^{9}$ used the slurry technique to prepare disorderly exfoliated nanocomposites. In this approach a soft siloxane surfactant with a molar mass of $1900 \mathrm{~g}$ $\mathrm{mol}^{-1}$ was adopted to modify the clay. The modified clay slurry was then mixed with the silicone rubber by hand and exfoliation was achieved. An similar approach was used by Kurian et al. ${ }^{10}$ to prepared polystyrene nanocomposites, in which a tailor-made polystyrene surfactant was used to modify montmorillonite clays. In this case, the characterization of the modified clays and the resulting nanocomposites showed that only a phase-separation occurred, without increase in the clay gallery distance.

Evidence of intercalation/delamination of montmorillonite clays in silicone fluids, ${ }^{11,12}$ without any solvent assistance or shear, ${ }^{13}$ associated to the nature of the bonding and to the highly unusual surface properties of poly(dimethylsiloxane), PDMS, motivated the use of this polymer as swelling (or intercalating) agent in layered silicates, giving rise to silicone/clay slurries.

There are a wide variety of commercial silicone copolymers that could act as swelling agents in layered clays. In this work, we investigated the potential use of three different silicone fluids as swelling agents for montmorillonite clays. The resulting morphologies of the silicone/clay slurries were evaluated by small-angle/wideangle X-ray scattering (SAXS/WAXS) techniques. The modified clays were easily prepared by mechanical stirring and could be later explored as masterbatches to reinforce silicone rubbers or other silicone-based materials.

\section{Experimental}

\section{Materials}

Two montmorillonite clays were used in this work: a natural montmorillonite (MMT) and an organic montmorillonite (O-MMT). The MMT GEL MAX 400, supplied by Eduardo Vasconcelos Representações LTDA (Porto Alegre, Brazil), is a polycationic clay with a cation exchange capacity of 106 mequiv./100 g and a real density of $1.54 \mathrm{~g} / \mathrm{cm}^{3}$. The elemental composition (wt. $\%$ ) of this MMT clay determined by X-ray fluorescence is: $\mathrm{SiO}_{2}$ (60.8), $\mathrm{Al}_{2} \mathrm{O}_{3}(27.4), \mathrm{Fe}_{2} \mathrm{O}_{3}(2.4), \mathrm{TiO}_{2}(0.4), \mathrm{MgO}$ (2.7), $\mathrm{CaO}$ (2.9), $\mathrm{K}_{2} \mathrm{O}$ (3.0), others (0.4). O-MMT was purchased from Bentec (Livorno, Italy) and it is commercially available as Viscogel ED. Viscogel ED (OMMT) is a chemically modified montmorillonite having a long chain quaternary alkyl ammonium salt, which increases the clay gallery distance and makes it compatible with hydrophobic polymers. The silicone fluids used to prepare the MMT and O-MMT slurries were supplied by Dow Corning do Brasil (Hortolândia, Brazil). The general characteristics of these fluids and their corresponding nomenclatures are shown in Table 1. PDMS-NH $\mathrm{NH}_{2}$ is a silicone/water emulsion with water content of 72 wt. \%, as determined by thermogravimetry.

\section{Preparation of the silicone/clay slurries}

MMT or O-MMT was mechanically blended with each silicone sample in a Marconi MA039 mechanical stirrer at 
Table 1. General characteristics of the silicone samples

\begin{tabular}{|c|c|c|c|}
\hline Silicone sample & Molar mass / (g mol) & Water content $(\%)$ & Acronym/Structure \\
\hline poly(dimethyl- & 4676 & - & PDMS-OH \\
\hline
\end{tabular}
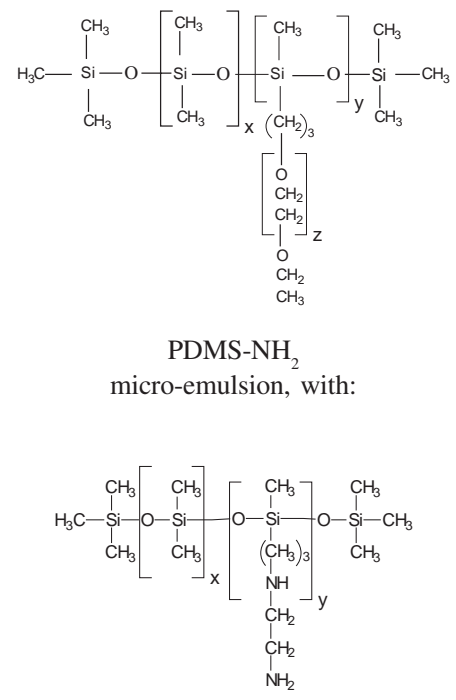

$160 \mathrm{rpm}$ for $20 \mathrm{~min}$ in a $1: 1(\mathrm{~m} / \mathrm{m})$ ratio. This step resulted in 6 dispersions: MMT/PDMS-OH; MMT/PDMS-PEO; MMT/PDMS-NH $;$; O-MMT/PDMS-OH; O-MMT/PDMS$\mathrm{PEO}$ and $\mathrm{O}-\mathrm{MMT} / \mathrm{PDMS}-\mathrm{NH}_{2}$. The clays were dried in a vacuum oven at $100{ }^{\circ} \mathrm{C}$ for $16 \mathrm{~h}$ prior to characterization and preparation of the silicone/clay slurries.

\section{Sample characterization}

The X-ray scattering experiments were all performed at the D11A-SAXS1 beamline of the National Synchrotron Light Laboratory, LNLS (Campinas-SP, Brazil). At this workstation, the X-ray beam is horizontally focused and monochromatized by a curved (111) silicon crystal. The wavelength used was $\lambda=1.608 \AA$. The beam was defined by two sets of slits. In the SAXS experiments, the silicone samples were injected into a $1 \mathrm{~mm}$ thick sample-holder. For these experiments a one-dimensional position sensitive detector was used with a sample-to-detector distance of $729 \mathrm{~mm}$. In the 2D-SAXS/WAXS experiments the samples (clay powders and silicone/clay slurries) were spread with a spatula on a mica sheet, sanduiched by another mica, and then inserted into a sample-holder. The sample-todetector distance used was $477.5 \mathrm{~mm}$. The measurements were collected with a two dimensional imaging plate and the scattering profiles were obtained from radial integration of the images. For the samples with an anisotropic behavior the integration was taken from oriented sectors and for the samples with an isotropic behavior the whole image was integrated. For both scattering experiments the measurements were taken at $25^{\circ} \mathrm{C}$. Background scattering was subtracted from the total intensity to eliminate any contribution from the silicone fluids. The scattering profiles were also corrected for sample absorption and detector response.

\section{Results and Discussion}

Morphological evaluation of the silicone fluids

No significant small angle scattering was observed for the PDMS-OH fluid. The absence of scattering suggests that this is a highly homogeneous fluid. In other words, the polar $-\mathrm{Si}\left(\mathrm{CH}_{3}\right)_{2} \mathrm{OH}$ end-groups of the apolar PDMS chains are not able to induce the formation of organized entities or a phase contrast that would produce scattering. The scattering profile for PDMS-PEO is shown in Figure 1. The observed scattering for PDMS-PEO was attributed 
to the difference in the electronic densities promoted by the organization of the polar polyether branches and the apolar siloxane main chains in the fluid. For the PDMS$\mathrm{NH}_{2}$, the scattering profile (not shown) was similar to that obtained for PDMS-PEO. In this case, the scattering was attributed to the structures formed by auto-organization of the PDMS- $\mathrm{NH}_{2}$ amphiphilic polymeric molecules in the water dispersion.

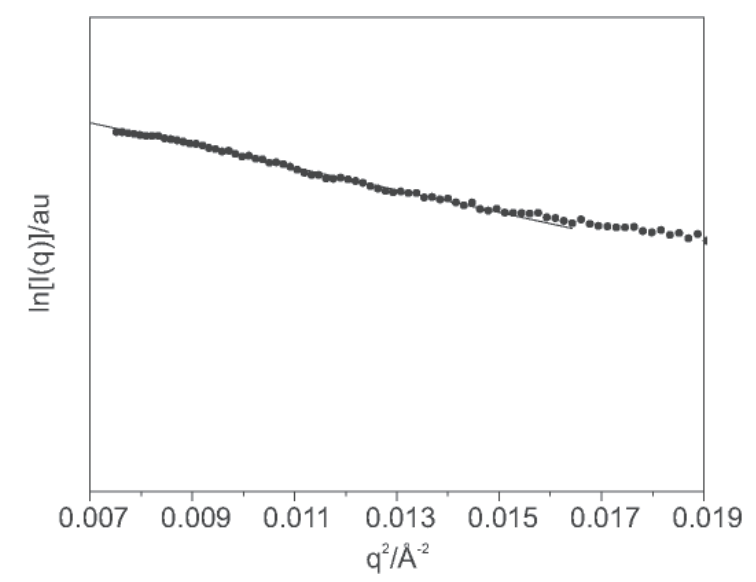

Figure 1. Correct SAXS intensity profile for PDMS-PEO. The straight line represents the linear fit used to obtain $R_{g}$ in the Guinier region.

The size of the scattering domains in a sample can be calculated using Guinier's law assuming a homogeneous and dilute system. The radius of gyration of the scatterers can be calculated using Guinier's approximation, according to which the dependence of SAXS intensity $(I)$ with the modulus of the scattering vector $q(q=(4 \pi / \lambda) \sin \theta$, where $\lambda=\mathrm{X}$-ray wavelength and $q=$ one half of the scattering angle) can be described by the following relationship,,$^{14}$

$$
I(q) \propto \exp \left(\frac{-q^{2} R_{g}^{2}}{3}\right)
$$

where $R_{g}$ is the radius of gyration of the scattering particles.

From a plot of $\ln (I)$ versus $q^{2}$, a straight line can be obtained and $R_{g}$ can be calculated from the slope $\left(\alpha=R_{g}^{2} / 3\right)$.

For particles that are assumed to be spherical, the radius $(r)$ can be calculated from the following equation:

$$
R_{g}=\sqrt{\frac{3}{5}} r
$$

The calculated radii for the scattering centers in PDMS- $\mathrm{NH}_{2}$ and PDMS-PEO fluids were $185 \AA$ and $32 \AA$, respectively. In both cases the particle systems were polydisperse. In this condition, the experimental curves depart from linearity and become concave. For this reason the calculated radii for PDMS- $\mathrm{NH}_{2}$ and PDMS-PEO fluids represent only an estimation of the maximum possible radius size.

\section{Morphological evaluation of the silicone/clay slurries}

\section{D-SAXS/WAXS patterns}

The 2D-SAXS/WAXS technique is useful in determining both gallery size and relative orientation of the layered silicate in a polymeric matrix. This technique allows evaluation of the tactoid thickness and the number of the stacked layers. Recent papers reporting results on this topic have been those by Vaia et al., ${ }^{15}$ Pizzey et al. ${ }^{16}$ and Causin et al. ${ }^{17}$ The low angle range evaluation is especially important to check the conditions where the clay basal peaks of the sample disappear, which is considered an appropriate sign of exfoliation.

Reflections and orientations of different structural features for the clay powders and for the silicone/clay slurries could be identified in the 2D-SAXS/WAXS patterns shown in Figure 2 as: (1) unmodified montmorillonite 001 plane and (2) modified (intercalated) montmorillonite 001 plane.

The silicone/clay slurries presented a smaller ring diameter in relation to the unmodified clay 001 reflection (clay powders), which was associated to an increase in the gallery distance of the clay layers in the slurries. A more detailed explanation for this fact is given in the following paragraphs.

MMT, O-MMT, MMT/PDMS-OH and O-MMT/ PDMS-OH produced an isotropic scattering pattern (Figure 2(a), 2(e), 2(b) and 2(f), respectively). On the other hand, a shear induced morphology with a ring in the center and oriented surrounding arcs were observed for the MMT and O-MMT dispersions prepared with PDMS-NH $\mathrm{N}_{2}$ and PDMSPEO fluids (Figure 2(c), 2(d), 2(g) and 2(h)). This behavior indicated a preferential orientation of the clay particles immersed in these polymeric fluids, showing that the platelets responded to the shear effect promoted by the spreading of the samples on the mica sheets. This observation is experimentally reproductible and can be obtained following the procedure described in the experimental section. In addition, the patterns illustrated in Figure 2(c) and 2(d) did not show perfect circular rings. On the contrary, the rings were distorted in an elliptical form, which is associated with a 3D-crystalline lattice distortion of the platelets, as illustrated in Figure 3. In other words, the shear effect not only led to the platelet orientation but also caused a deformation of the crystallographic domains along a single macroscopic axis. ${ }^{18}$ 

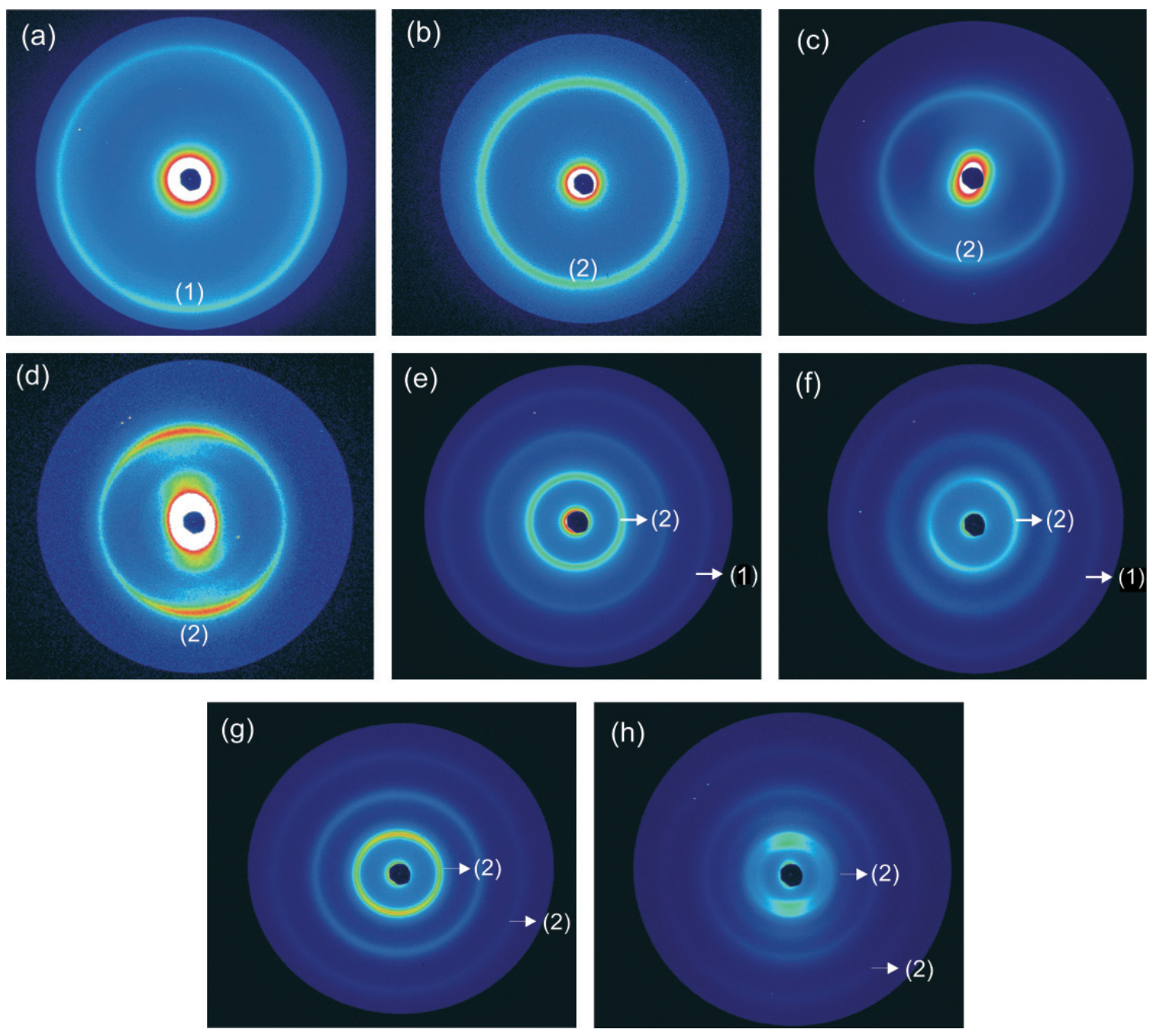

Figure 2. 2D-SAXS/WAXS patterns for the clay powders and the silicone/clay slurries: (a) MMT; (b) MMT/PDMS-OH; (c) MMT/PDMS-NH ${ }_{2}$; (d) MMT/ PDMS-PEO; (e) O-MMT; (f) O-MMT/PDMS-OH; (g) O-MMT/ PDMS- $\mathrm{NH}_{2}$; (h) O-MMT/ PDMS- PEO.

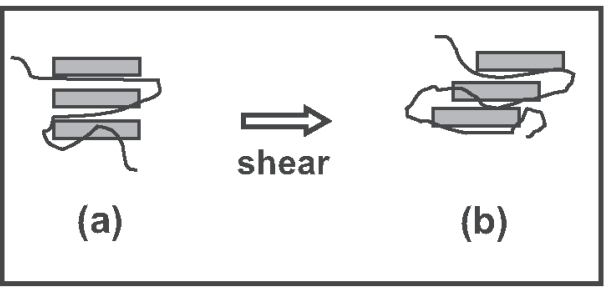

Figure 3. Schematic representation of: (a) non-distorted crystalline lattice, (b) distorted crystalline lattice.

The one-dimensional $I(\mathrm{q}) v s$. q plots presented in Figure 4 resulted from the radial integration of the 2D data shown in Figure 2.

\section{WAXS region analyses $\left(q>0.23 \AA^{-1}\right)$}

The MMT clay structure is characterized by a (001) d-spacing of $12.6 \AA$, corresponding to a strong Bragg reflection peak at $\mathrm{q}=0.5 \AA^{-1}$ in the WAXS region. The O-MMT clay exhibited d-spacing of $12.6 ; 18.5$ and 34.9
$\AA$ corresponding to the basal plane reflections at $\mathrm{q}=0.5$; 0.34 and $0.18 \AA^{-1}$, respectively. The diffraction peak at $\mathrm{q}$ $=0.34 \AA^{-1}(\mathrm{~d}=18.5 \AA)$ is attributed to a second order reflection. ${ }^{19}$

For the silicone/clay slurries the diffraction peak was shifted to lower values in the WAXS region $\left(q>0.23 \AA^{-1}\right)$, indicating the insertion of the fluids between the clay layers. The extent of fluid penetration into the galleries varied according to the nature of the silicone fluid and type of clay. The MMT clay showed a greater tendency to swell than O-MMT. In general, one can expect that clays with larger layer spacing may lead to greater swelling, since the platelet-platelet attraction is reduced. In addition, the diffusion of polymer chains inside organic modified-clay galleries can be less hindered due to the increased spacing, which leads to improved intercalation. However, this represents an oversimplified picture, since intercalation is highly dependent upon a variety of factors, e.g. thermodynamic interactions (between polymer-clay, 
Table 2. d-Spacing values for clays and clay/slurries obtained from the 2D-SAXS/WAXS experiment

\begin{tabular}{lc}
\hline sample & d-spacing $(\AA)$ \\
\hline MMT & 12.6 \\
MMT/PDMS-PEO & $18.1 ; 23.6$ \\
MMT/PDMS-NH & 18.9 \\
MMT/PDMS-OH & 15 \\
O-MMT & $12.6 ; 18.5 ; 34.9$ \\
O-MMT/PDMS-PEO $_{\text {O-MMT/PDMS-NH }_{2}}^{13.3 ; 20.3 ; 27.1 ; 41.7 ; 52.5}$ \\
O-MMT/PDMS-OH & $13.2 ; 19.6 ; 39.2$ \\
\hline
\end{tabular}

polymer-surfactant, and clay-clay), clay stability, packing density etc. ${ }^{20}$ The silicone fluids used in this study exhibited good affinity for the polar surface of MMT clay. On the other hand, the hydrocarbon-like environment at the O-MMT surface limited the access of the polymeric segments from the silicone fluids to the silicate surface, thereby shielding silicone fluid-silicate surface interactions. These results agree with the thermodynamic
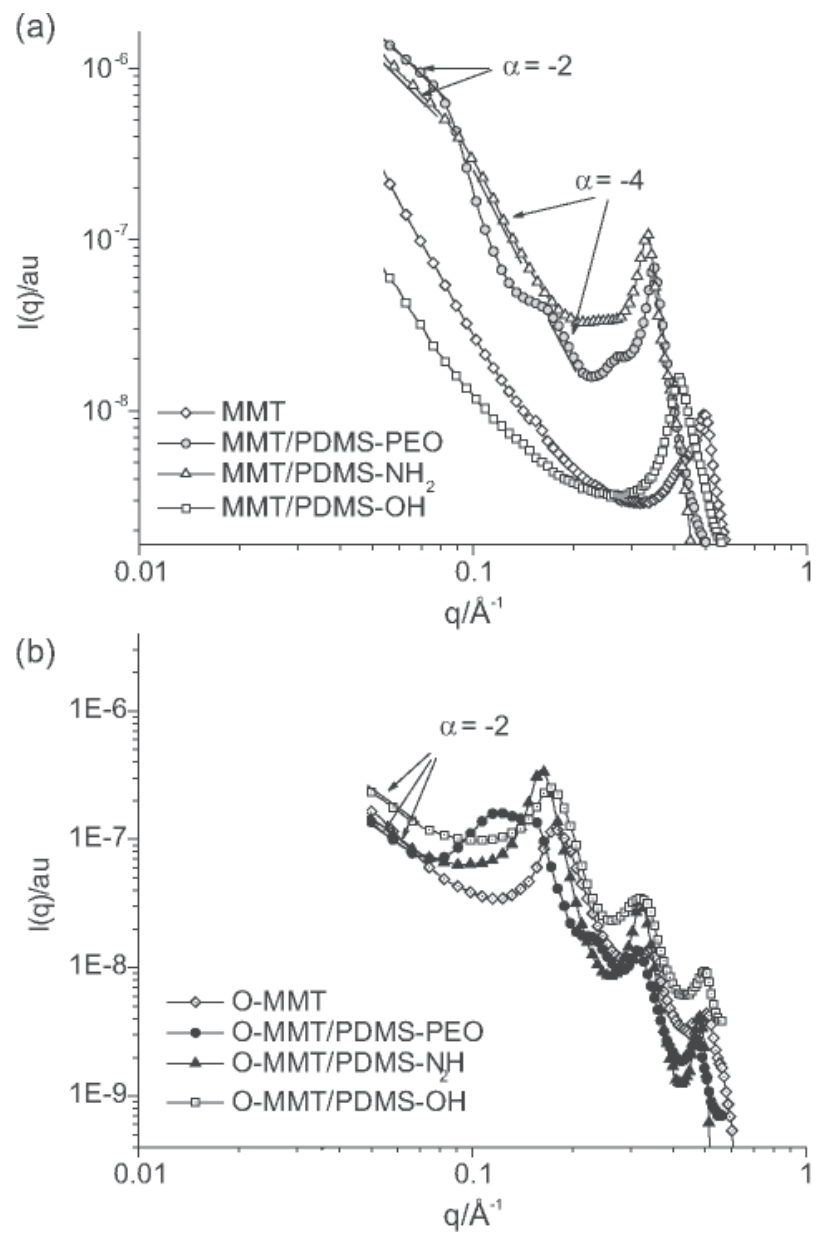

Figure 4. SAXS/WAXS profiles for the clay powders and the silicone/ clay slurries. (a) MMT; MMT/PDMS-OH; MMT/PDMS-NH ${ }_{2}$; MMT/ PDMS-PEO; (b) O-MMT; O-MMT/PDMS-OH; O-MMT/ PDMS- $\mathrm{NH}_{2}$; O-MMT/ PDMS- PEO analysis and molecular modeling described by Vaia and Giannelis $^{21}$ and Tanaka and Goettler. ${ }^{22}$ Based on their lattice model for polymeric melt intercalation, the former authors concluded that desirable changes in the energy of interactions are achievable by the maximization of the number of favorable polymer-silicate interactions and the minimization of unfavorable non-polar interactions between polymer and alkyl-type surfactants on the silicate surface. These favorable interactions are believed to provide the driving force for polymer intercalation. Tanaka and Goettler ${ }^{22}$ predicted binding energies for polyamide nanocomposites using molecular modeling. Their results showed that the surfactant shields the polyamide-clay interactions and that larger surfactant molecules result in larger shielding effects. The polyamide-clay binding energy showed a maximum value for the pristine clay. This value decreased with the increase in the molecular volume of the surfactant.

Based on the above results, it is concluded that the conversion of the normally hydrophilic silicate surface to an organophilic one (generally done by ion-exchange reactions with cationic surfactants) does not necessarily lead to larger clay swelling by a specific polymer. However, this effect depends on the polarity of the polymer.

PDMS-PEO and PDMS- $\mathrm{NH}_{2}$ showed greater tendencies to swell the galleries of the clays than the PDMS-OH fluid. For MMT $(\mathrm{d}=12.6 \AA)$ the $\mathrm{d}$ values of the slurries reach $18.1 \AA, 18.9 \AA$ and $15 \AA$, respectively. In addition to the d-spacing of $18.1 \AA$ for the PDMS-PEO slurry, a new basal reflection at $q=0.27 \AA^{-1}$ was found, indicating a new population of clays with d of $23.6 \AA$. This basal reflection is too broad to be explained by the interference effect and the difference between them does not agree with the interference rule for lamellar structures. ${ }^{23}$ The effect of the nature of the silicone fluid on gallery swelling for O-MMT followed the same trend found for the MMT clay. Similarly, new basal reflections appeared for the O-MMT slurry prepared with PDMSPEO fluid at $\mathrm{q}=0.23 \AA^{-1}$ and $0.12 \AA^{-1}$, corresponding to layer distances of approximately $27.1 \AA$ and $52.5 \AA$, respectively.

The pronounced swelling effect of the PDMS-NH $\mathrm{N}_{2}$ and PDMS-PEO in MMT layers could be attributed to a larger number of interaction points for these silicone fluids, compared to PDMS-OH. In the PDMS-OH, the favorable interactions are restricted to the chain ends, through hydrogen bonds with the structural oxygen of the clay layers or with the $\mathrm{Si}-\mathrm{OH}$ groups from the layer edges. In PDMS-PEO, the driving force for intercalation and swelling of the layers could be attributed to the formation 
of coordination complexes between the interlayer cations (mainly $\mathrm{Mg}^{2+}, \mathrm{K}^{+}$and $\mathrm{Ca}^{2+}$ ) and the oxygen of the $-\left(\mathrm{CH}_{2} \mathrm{CH}_{2} \mathrm{O}\right)_{n}$ polar segments grafted onto the main siloxane chain (Figure 5). This proposal is based on the intercalation model of Aranda and Hitzky ${ }^{24}$ and Budjak et al. ${ }^{25}$ for poly(ethylene oxide)/montmorillonite nanocomposites. Since the coordination mechanism requires the release of the interlayer water, an entropic contribution could also take place. However, full replacement of the water molecules in the coordination environment does not seem likely. Poly(ethylene oxide) (PEO) cannot play the role of a bridge in the electrostatic attraction between cations and basal oxygen atoms of the silicate layer, as water molecule dipoles do. ${ }^{25}$ In contrast to these proposals, Parffit and Greenland ${ }^{26}$ have suggested that the gallery ions are not directly associated with the PEO oxygen atoms and that their interactions with the polymer are mediated by the water molecules from their original hydration shells.

In the PDMS- $\mathrm{NH}_{2}$ fluid, the intercalation could be attributed to the effect of water on layer swelling. In addition, a contribution of hydrogen bonding between the $-\mathrm{NH}_{2}$ groups and the structural oxygen or the $\mathrm{Si}-\mathrm{OH}$ groups from the layer edges could also occur.
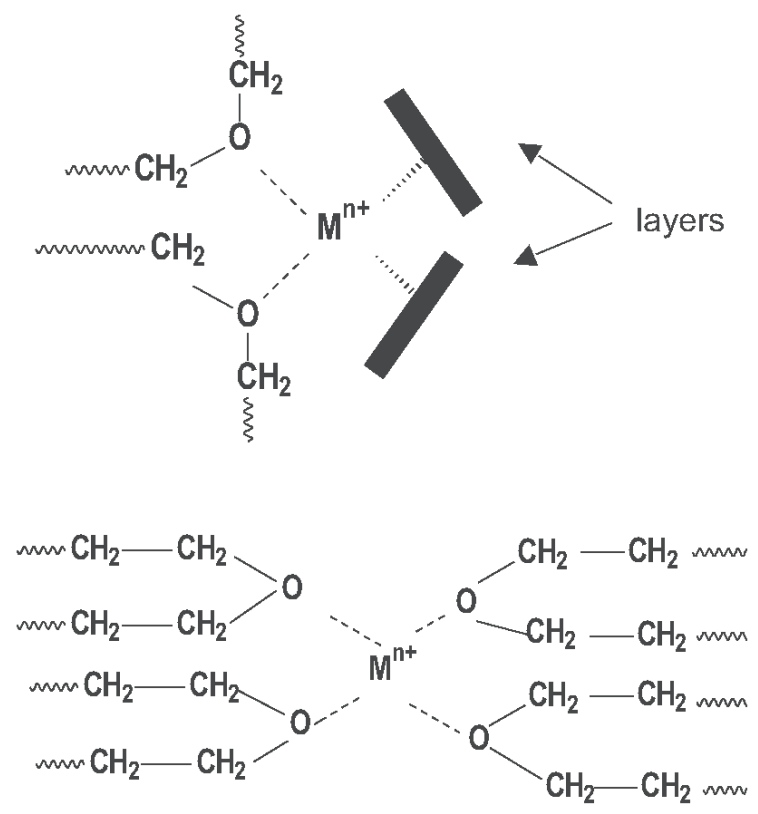

Figure 5. Schematic representations of PDMS-PEO intercalation models in montmorillonite clay. Where, $\mathrm{M}^{\mathrm{n}+}=\mathrm{Mg}^{2+}, \mathrm{K}^{+}$and $\mathrm{Ca}^{2+}$.

Favorable interactions between the clay surface and the silicone fluids containing functional groups contribute to their intercalation into O-MMT. LeBaron and Pinnavaia ${ }^{11}$ verified the importance of specific interactions between polysiloxane fluids and the gallery surface of an organic-modified layered silicate for polymer intercalation. These authors compared the intercalation of PDMS-SiOH and PDMS-Si $\left(\mathrm{CH}_{3}\right)_{3}$ with the same molar mass and found that the latter fluid did not intercalate into the organic-modified layered silicate.

SAXS region analyses $(q<0.23 \AA)$

In general, three regions can be recognized in the small angle scattering curves for layered flat particle systems, each of which is characterized by a particular slope $(a)$ on the plot of the logarithm of the intensity $I v s$. the logarithm of the scattering vector, $q$. In the first region, at very small $q$ values, the scattered intensity presents a $q^{-2}$ behavior, typical of non-interacting flat particles. ${ }^{14}$ In the second region (intermediate regime), there is a different angular dependence of the scattering intensity which gives information about possible fractal-like features of the scattering entities. In the third region (or final slope ${ }^{14}$ ), the dependence of $I$ on $q$ follows the well-known Porod's law and, in these conditions, $\alpha=-4$. This law is valid not only for non-interacting scattering particles, but also for densely packed particle systems, when they present a well defined smooth interface. ${ }^{14}$

From the slopes of the scattering curves for the MMT/ silicone dispersions (Figure 4(a)) further structural information could be obtained if the data are treated as the scattering from a two phase particle system. Other authors used a similar approach in the study of montmorillonite dispersions..$^{27,28}$

The MMT/PDMS-NH $\mathrm{N}_{2}$ and MMT/PDMS-PEO dispersions showed at a very small $q$ region an $\alpha=-2$ behavior, suggesting the existence of thin platelets, constituted by single layers or a stacking of few layers. Similar observations were also reported by Leach et al..$^{27}$ for montmorillonite/toluene dispersions. The X-ray scattering results for MMT/PDMS-NH $\mathrm{N}_{2}$ and MMT/PDMSPEO suggested that these dispersions are constituted by expanded tactoids (intercalated morphology) and thin platelets. These results agree with those described by Morvan et al. ${ }^{29}$ for montmorillonite/water dispersions at 20 wt.\%. These authors concluded that there was a nonuniform arrangement of the clay particles in the montmorillonite dispersions. The existence of relatively more concentrated regions containing aligned particles (with the observed interparticle separation) and less concentrated regions containing particles with random orientations was proposed. This observation is also similar to the montmorillonite dispersions reported by Langmuir, ${ }^{30}$ who found that montmorillonite gels could be separated into an anisotropic and an isotropic phase, the last one with lower concentrations. For the MMT/PDMS-OH dispersion, the absence of the $\alpha=-2$ behavior in the 
scattering curve indicated the occurrence of interactions between the particles. ${ }^{31}$

The $I(q)$ dependence for the intermediate regime of the MMT/PDMS-OH dispersion curve showed a $\alpha=-3$ behavior. Yoonessi et al. ${ }^{32}$ correlated this angular dependence with platelets and tactoids of various thickness, which are bent and curved (fractal contribution to shape). The dispersed microstructure of the clays proposed by Yoonessi et al. ${ }^{32}$ ( $\alpha=-3$ behavior, fractal contribution) was characterized by small-angle neutron scattering (SANS) and this interpretation can be extended to SAXS.

(a)

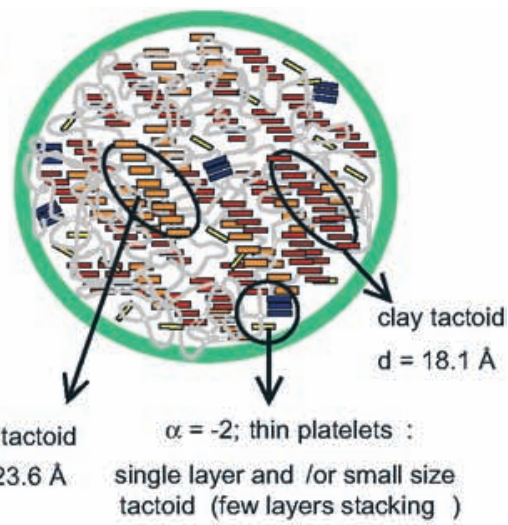

(b)

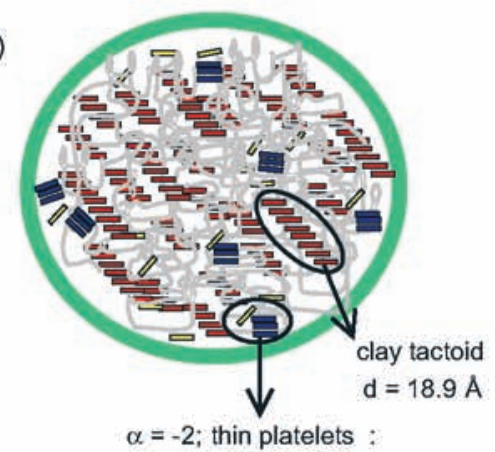

single layer and /or small size tactoid (few layers stacking )

(c)

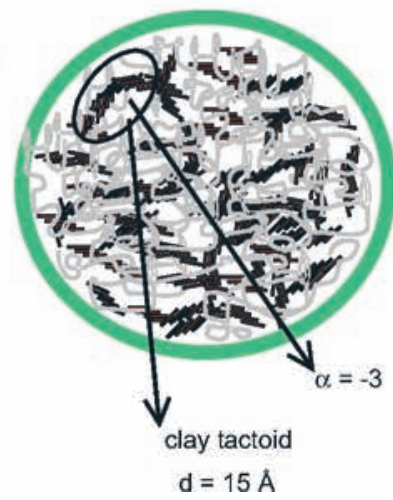

Figure 6. Simplified morphologies for the MMT slurries: (a) MMT/ PDMS-PEO; (b) MMT/PDMS-NH ${ }_{2}$; (c) MMT/PDMS-OH.
From the final slope, the $\alpha=-4$ dependence for $I(q)$ (Porod's law) was observed for the MMT/PDMS-NH dispersion, indicating the presence of well defined particles with smooth interfaces in the clay slurry. For MMT/PDMS-PEO, the scattering curve was slightly concave at this point and the transition to $\alpha=-4$ was not sharp. From 2D-SAXS/WAXS data interpretation, simplified morphologies were built for the MMT slurries, as can be seen in Figure 6.

For the O-MMT/silicone dispersions (Figure 4(b)), similar analyses from the slopes of the scattering curves showed a dependence of $I(q)$ following $\alpha=-2$ for all three dispersions. No intermediate regime or Porod's law behavior was observed for these dispersions.

\section{Conclusions}

The effect of different silicone fluids on montmorillonite clay/silicone slurries was studied. The extent of swelling in the clay galleries varied according to the nature of the silicone fluid and clay. O-MMT showed a lower tendency for gallery swelling than MMT due to the hydrocarbon-like environment on the layer surface that shields the intercalation of the fluid into the clay. A more pronounced layer separation effect was found for PDMS$\mathrm{NH}_{2}$ and PDMS-PEO. This result was attributed to increase in the fluid-layer surface interactions compared to PDMS$\mathrm{OH}$, for which the favorable interactions are restricted to only the chain ends. Analyses of the scattering profiles in the WAXS and SAXS regions showed that the resulting morphology of the MMT dispersions prepared with the PDMS-NH $\mathrm{N}_{2}$ and PDMS-PEO consists of a hierarchical structure formed by primary features associated with thin platelets and secondary features associated with an arrangement of expanded tactoids. Similar trends were also found in the O-MMT/silicone dispersions.

\section{Acknowledgment}

The authors acknowledge financial support from FAPESP (Proc. No. 2003/009926-1) and CNPq (Proc. No. 473670/2004-6 and 142091/2004-9). We are also grateful for the Laboratório Nacional de Luz Síncrotron (LNLS) for facilitating the 2D-SAXS/WAXS measurements on beamline D11-1-A.

\section{References}

1. Negrete, H. N.; Letoffe, J. M.; Putaux, J. L.; David, L.; Bourgeat-Lami, E.; Langmuir 2004, 20, 1564.

2. Alexandre, M.; Dubois, P.; Mat. Sci. Eng. R. 2000, $28,1$. 
3. Ray, S. S.; Okamoto, M.; Prog. Polym. Sci. 2003, 28, 1539.

4. Manias, E.; Chen, H.; Krishnamoorti, R.; Genzer, J.; Kramer, E. J.; Giannelis, E. P.; Macromolecules 2000, 33, 7966.

5. Hasegawa, N.; Okamoto, H.; Kato, M.; Usuki, A.; Sato, N.; Polymer 2003, 44, 2933.

6. Ma, J.; Yu, Z. Z.; Zhang, Q. X.; Xie, X. L.; Mai, Y. W.; Luck, I.; Chem. Mater. 2004, 757.

7. Chen, B.; Liu, J.; Chen, H.; Wu, J.; Chem. Mater. 2004, 16, 4864.

8. Wang, K.; Chen, L.; Wu, J.; Toh, M. L.; He, C.; Yee, A. F.; Macromolecules 2005, 38, 788.

9. Ma, J., Yu, Z.; Kuan, H.; Dasari, A.; Mai, Y.; Macromol. Rapid Commun. 2005, 26, 830.

10. Kurian, M.; Dasgupta, A.; Beyer, F. L.; Galvin. M. E.; J. Polym. Sci. Part B: Polym. Phys. 2004, 4075.

11. LeBaron, P. C; Pinnavaia, T. J.; Chem. Mater. 2001, 13, 3760.

12. Wang, S.; Long, C.; Wang, X.; Li, Q.; Qi, Z.; J. Appl. Polym. Sci. 1998, 69, 1557.

13. Zhang, L. M.; Jahns, C.; Hsiao, B.; Chu, B.; J. Colloid Interf. Sci. 2003, 266, 339.

14. Glatter, O. In Small Angle X-ray Scattering; Glatter, O.; Kratky, O., eds.; Academic Press: New York, 1982, pp. 3-17.

15. Vaia, R.A.; Liu, W.D.; Koerner, H.; Polym. Sci. Polym. Phys. Ed. 2003, 41, 3214.

16. Pizzey, C.; Klein, S.; Leach, E.; van Duijneveldt, J.S.; Richardson, R. M.; J. Phys.: Condens. Mater. 2004, 16, 2479.

17. Causin, V.; Marega, C.; Marigo, A.; Ferrara, G.; Polymer 2005, 46, 9533.
18. Finnefrock, A. C.; Ulrich, R.; Toombes, G. E. S.; Gruner, S. M.; Wiesner, U.; J. Am. Chem. Soc. 2003, 125, 13084.

19. Khatib, K.; Pons, C. H; Bottero, J.Y.; François, M.; Baudin, I.; J. Colloid Interf. Sci. 1995, 172, 317.

20. Fornes, T. D.; Yoon, P. J.; Hunter, D. L.; Keskkula, H.; Paul, D. R.; Polymer 2002, 43, 5915.

21. Vaia, R.; Giannelis, E.; Macromolecules 1997, 30, 7990.

22. Tanaka, G.; Goettler, L. A.; Polymer 2001, 43, 541.

23. Vaia, R. A.; Liu, W.; J. Polym. Sci. Pol. Phys. 2002, 40, 1590.

24. Aranda, P.; Hitzky, E. R.; Chem. Mater. 1992, 4, 395.

25. Bujdak, J.; Hackett, E.; Giannelis, E. P.; Chem. Mater. 2000, 12, 2168.

26. Parffit, R.L.; Greenland, D. J.; Clay Miner. 1970, 8, 305.

27. Leach, E.S.H.; Hopkinson, A.; Franklin, K; van Duijneveldt, J. S.; Langmuir 2005, 21, 3821.

28. Hight, R.; Highdon, W. T.; Schmidt, P. W.; J. Chem. Phys. 1960 , 33, 1656.

29. Morvan, M.; Espinat, D.; Lambard, J.; Zemb, T. H.; Colloid Surf. A 1994, 82, 193.

30. Langmuir, I.; J. Chem. Phys. 1938, 6, 873.

31. Guinier, A. In Small-Angle Scattering of X-rays; Guinier, A.; Fournet, G., eds.; John Wiley and Sons: New York, 1955, ch. 2.

32. Yoonessi, M.; Toghiani, H.; Dauloton, T. L.; Lin, J. S.; Pittman, C.U.; Macromolecules 2005, 38, 818.

Received: August 7, 2006

Web Release Date: July 4, 2007

FAPESP helped in meeting the publication costs of this article. 